\title{
Calcium Pre-Rinse: Effect on permeability of dentin tubules by fluoride rinse
}

\author{
Tacíria-Machado-Bezerra Braga ${ }^{1}$, David-Nascimento Braga ${ }^{2}$, Edilausson Moreno-Carvalho ${ }^{3}$, José-Roberto-de \\ Oliveira Bauer $^{4}$, Cecilia-Pedroso Turssi ${ }^{5}$
}

${ }^{1}$ DDS, MSc, PhD student, Faculdade São Leopoldo Mandic - Instituto de Pesquisas São Leopoldo Mandic, Campinas, SP, Brazil; Assistant professor, Faculty of Dentistry, CEUMA University, São Luís, MA, Brazil

${ }^{2}$ DDS, Specialist in Oral and Maxillofacial Surgery

${ }^{3}$ DDS, MSc, PhD student, Faculty of Dentistry, Federal University of Maranhão, São Luís, Brazil

${ }^{4}$ DDS, MSc, PhD, Associate Professor, Federal University of Maranhão, São Luís, Brazil

${ }^{5}$ DDS, MSc, PhD, Professor, Faculdade São Leopoldo Mandic - Instituto de Pesquisas São Leopoldo Mandic, Campinas, SP, Brazil

Correspondence:

Av. Do Vale, 9 - Ed. Carrara S-415

$J d$. Renascença - São Luis, MA, Brasil

CEP: 65075-660

taciria_mb@hotmail.com

Ranjbar MA, Ranjbar Z, Zahed M, Nikookar N. CD73 a novel marker for the diagnosis of benign and malignant salivary gland tumors. J Clin Exp Dent. 2019;11(4):e303-9.

Received: 26/10/2018 http://www.medicinaoral.com/odo/volumenes/v11i4/jcedv11i4p303.pdf

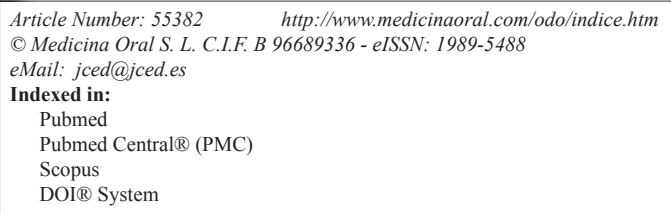

\begin{abstract}
Background: The aim of this study was to evaluate whether calcium $(\mathrm{CaL})$ solution would enhance the capacity of sodium fluoride $(\mathrm{NaF})$ solution in reducing the permeability of hypersensitive dentin.

Material and Methods: Thirty-two Wistar rats ingested for 45 days acidic isotonic drink (Gatorade, $\mathrm{pH}$ 2.7) ad libitum to induce dental erosion. Then, molar teeth received a cold stimulus to confirm the presence and score the intensity of dentin hypersensitivity based on body contraction and noise. Animals were allocated to four groups $(\mathrm{n}=8)$, according to the solution(s) applied in the oral cavity: $\mathrm{NaF}(12 \mathrm{mmol} / \mathrm{L}, 1 \mathrm{~min})$; $\mathrm{CaL}(150 \mathrm{mmol} / \mathrm{L}, 1 \mathrm{~min})$; $\mathrm{CaL}$ followed by $\mathrm{NaF}(\mathrm{CaF}+\mathrm{NaF}, 1$ min each); distilled water (DW, 1 min, as negative control). The animals were euthanized and the mandibles dissected into hemimandibles, which were sealed with sticky wax, except for the occlusal surface of the molar teeth. The samples were immersed in $10 \%$ copper sulphate solution and in $1 \%$ dithioxamide alcoholic solution ( $25 \mathrm{~min}$ each). The samples were sectioned longitudinally and imaged under optical microscope. Then, dentin permeability was measured as the area of copper ion penetration, using ImageJ software. Photomicrographs were obtained by scanning electron microscopy.

Results: $68.7 \%$ of animals had body contraction associated or not with noise. One-way ANOVA followed by Tukey's test indicated that groups treated with NaF solution, whether or not preceded by CaL solution, presented lower permeability than the remaining groups [CaL+NaF: $3405.7 \mu \mathrm{m}^{2}( \pm 1796.4)$; $\mathrm{NaF}: 4111.7 \mu \mathrm{m}^{2}( \pm 2450.6)$; CaL: 42254.6 $\mu^{2}( \pm 30399.2)$; DW: $\left.37064.6 \mu \mathrm{m}^{2}( \pm 21994.4)\right]$. Photomicrographs showed that $\mathrm{CaL}+\mathrm{NaF}$ group presented an increased proportion of occluded dentin tubules in comparison to the NaF-only group.

Conclusion: Although qualitatively there seems to be a benefit in using CaL pre-rinse, this solution did not quantitatively enhance the capacity of $\mathrm{NaF}$ in reducing permeability of hypersensitive dentin.
\end{abstract}

Key words: Dentin hypersensitivity, Fluoride, Calcium lactate, Animal model. 


\section{Introduction}

Although there has been a decline in the prevalence of caries lesions (1), an increase in non-carious lesions has been observed $(2,3)$. These are mainly the result of erosive, abrasive and fatigue wear (3). Clinically, these lesions may impair functional and aesthetic and cause negative impacts on quality of life (4), since they are associated with dentin hypersensitivity (DH) $(5,6)$.

$\mathrm{DH}$ is considered a common oral health problem, affecting about $35 \%$ of the population, with higher prevalence among females (7). It is characterized by acute and short duration pain due to the exposure of dentin, usually caused by erosive and/or abrasive lesions, in response to thermal, tactile, evaporative or chemical stimuli (8). In order to eliminate or minimize pain discomfort, there are two treatment approaches: modification or blocking of the pulpal nerve response and occlusion of exposed dental tubules, reducing dentin permeability (8).

Fluoridated products, including sodium fluoride $(\mathrm{NaF})$ solutions, are among the strategies intended to chemically occlude dentin tubules (9). Their mechanism of action relies on the formation of calcium fluoride (CaF2) like minerals, which can partially occlude dentin tubules (10).

Owing to the fact that calcium lactate solution $(\mathrm{CaL})$ pre-rinse enhances $\mathrm{NaF}$ effect even under erosive challenges $(11,12)$, it could be assumed that $\mathrm{CaL}$ might have the capacity to optimize the protection performed by $\mathrm{NaF}$ in managing $\mathrm{DH}$. Thus, the aim of this study was to evaluate whether CaL would enhance the capacity of $\mathrm{NaF}$ in reducing the permeability of hypersensitive dentin.

\section{Material and Methods}

-Experimental design

For this study, 32 male Wistar rats (Rattus Norvegicus) with 36-42 days of age and average weight of $400 \mathrm{~g}$ (Anilab Laboratory, Paulínia, SP, Brazil) with hypersensitive dentin were allocated to four groups $(\mathrm{n}=8)$ to receive the following solutions: 1) $\mathrm{NaF} ; 2$ ) $\mathrm{CaL} ; 3$ ) $\mathrm{CaL}$ followed by $\mathrm{NaF}(\mathrm{CaL}+\mathrm{NaF})$, and distilled water (DW), as negative control. The response variable was dentin permeability, measured in $\mu^{2}{ }^{2}$. Figure 1 depicts the flowchart of the experiment.

-Ethical aspects and conditioning of animals

After approval by the local Ethics Committee (protocol \#2016/016), animals were housed in groups of four each in polypropylene cages, bedded with wood shavings, in an open system in ventilated shelves, with controlled temperature of $24^{\circ} \mathrm{C}$. Photoperiod was 12 hours light and 12 hours dark, and commercial feed (Nuvital Co., São Paulo, SP, Brazil) was offered ad libitum.

-Induction of dentin hypersensitivity

In order to expose dentin tubules and induce hypersensitivity, the teeth of the animals were eroded using a va-

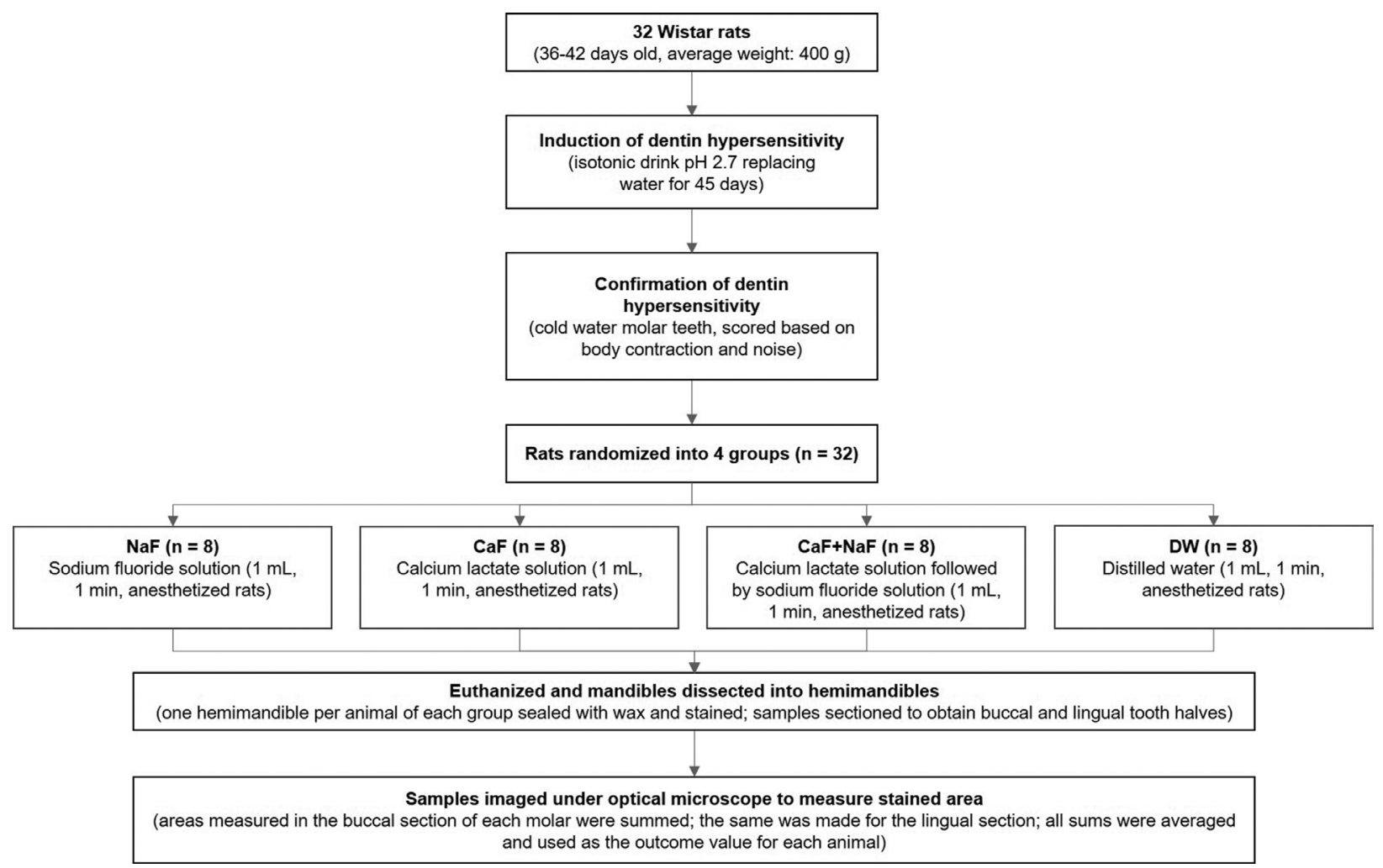

Fig. 1: Flowchart of the experiment. 
lidated model (13). In brief, animals ingested an acidic isotonic drink (Gatorade, lemon flavor, $\mathrm{pH}$ 2.7, Ambev, Jaguariúna, SP, Brazil), replacing drinking water for a period of 45 days (13). Solutions were packed in plastic bottles and changed daily.

On day 46, hypersensitivity induction was confirmed and scored by applying cold stimulus to molar teeth. For this, $0.5 \mathrm{~mL}$ of water at $4^{\circ} \mathrm{C}$ was applied with a syringe equipped with a metal cannula for $5 \mathrm{~s}$ on the buccal surface of the left second molar. The animal's response to pain was classified according to the following scores: 0 $=$ no response; $0.5=$ slight body contraction; $1=$ body contraction; 2 = strong body contraction and short noise; $3=$ strong body contraction and prolonged noise. All 32 animals presented pain signals and were therefore eligible to be randomly allocated to the groups (Fig. 1).

-Treatment application

Animals were allocated to four groups $(\mathrm{n}=8)$, according to the solution(s) applied in the oral cavity: $\mathrm{NaF}$; $\mathrm{CaL}$; $\mathrm{CaL}+\mathrm{NaF}$; DW.

Each animal was kept under dissociative anesthesia obtained by intramuscular injection of $50 \mathrm{mg} / \mathrm{Kg}$ Zoletil (Zoletil 50, Virbac do Brasil, São Paulo, SP, Brazil). Once anesthetized, each animal was positioned in dorsal decubitus, with the front and hind paws maintained in abduction, using a metal device. Elastics were gently attached to the upper and lower incisors, which kept the oral cavity open for treatment.

The oral cavity of the animals pertaining to the $\mathrm{NaF}$ group was exposed to $1 \mathrm{~mL}$ of a $228 \mathrm{ppm}(12 \mathrm{mmol} / \mathrm{L})$ $\mathrm{NaF}$ solution for $1 \mathrm{~min}$, while in the $\mathrm{CaL}$ group, a 150 $\mathrm{mmol} / \mathrm{L} \mathrm{CaL}$ solution was applied in the same volume and for the same 1-min duration. In the group in which $\mathrm{NaF}$ was preceded by $\mathrm{CaL}(\mathrm{Cal}+\mathrm{NaF})$, both solutions were applied as previously described. The oral cavity of the rats of the negative control group was exposed to distilled water. Solutions or distilled water was sucked from the oral cavity using 5-mL syringe and the teeth were gently dried with a gauze. In all groups, exposure to the respective treatment was performed in a single occasion.

-Euthanasia of animals

Immediately after treatment, each animal was euthanized with intramuscular injection of ketamine solution (200 mg/Kg body weight) and intraperitoneal injection of thiopental and lidocaine in the proportion of $150 \mathrm{mg} /$ $\mathrm{Kg}$ to $1 \mathrm{mg} / \mathrm{mL}$, respectively (14). The mandible were dissected, soft tissue trimmed and sectioned at the midline into hemimandibles.

-Dentin permeability

The effect of the treatments on dentin permeability was analyzed using a histochemical staining method (15). One hemimandible per animal of each group was sealed with stick wax in order to keep exposed only the occlusal surface. Subsequently, the hemimandibles were individually immersed in $10 \mathrm{~mL}$ of $10 \%$ copper sulphate solution for $25 \mathrm{~min}$ in an oven at $37 \pm 0.5^{\circ} \mathrm{C}$, dried on absorbent paper and immersed in $1 \%$ dithioxamide alcoholic solution for $25 \mathrm{~min}$. Finally, hemimandibles were rinsed with distilled water for $10 \mathrm{~s}$, dried and individually kept in a sealed container with cotton soaked in 0.5 $\mathrm{mL}$ ammonia for 7 days. Each stained hemimandible was fixed on an acrylic plate and sectioned longitudinally through its center to obtain sections of the buccal and lingual molars' halves using a precision saw (Isomet 1000, Buehler, Lake Bluff, IL, USA).

The cut surface of the molars of the two sections (buccal and lingual) of each hemimandible were imaged using an optical microscope (Nikon Eclipse-Ci Infinity 1-3C, Tokyo, Japan) under 40x magnification. The area presenting copper ions revealed by dithioxamide was measured in pixels and converted into $\mu \mathrm{m} 2$ using ImageJ (National Institute of Health, Bethesda, MD) by a single previously trained examiner. Each molar of the buccal section had their measured areas summed. The same was made for the lingual section. Then, all sums were averaged and used as the outcome value for each animal. The lower the penetration area, the lower the dentin permeability.

-Photomicrographs in scanning electron microscopy (SEM)

Sections representative of each group were allowed to dry in a desiccator for $48 \mathrm{~h}$, fixed in sample holder and analyzed under 50x, 250x, 500x, 1,000x, 2,000x and $5,000 \mathrm{x}$ magnifications using a scanning electron microscope (TM3030, Hitachi Chiyoda, Tokyo, Japan) operating at $15 \mathrm{KV}$. SEM photomicrographs were qualitatively evaluated for the presence, proportion of occluded dentin tubules and amount of deposits on dentin surface and tubules.

-Statistical analysis

The scores of DH-induced pain data were described by means of absolute and relative frequencies and median. The effect of treatments tested was evaluated using oneway analysis of variance and Tukey's test. The level of significance was set at 5\%. Statistical calculations were carried out with SPSS 23 (SPSS Inc., Chicago, IL, USA).

\section{Results}

While confirming DH induction, it was noticed that $68.7 \%$ of the rats had body contraction associated or not with noise (scores 1 to 3). Considering all animals, the pain median was 2 (Table 1). Figures $2 \mathrm{a}$ through c depict the exposure and wear of dentin surface and patent tubules 45 days after the consumption of the acidic isotonic drink.

One-way analysis of variance demonstrated statistically significant difference between groups regarding dentin permeability ( $p<0.001$, with $99.4 \%$ statistical power). The Tukey's test showed that dentin permeability was 
Table 1: Absolute (n) and relative (\%) frequency of pain scores after the induction of dentin hypersensitivity.

\begin{tabular}{|c|c|c|}
\hline Score & $\mathrm{n}$ & $\%$ \\
\hline 0 & 0 & 0.0 \\
\hline 0.5 & 10 & 31.3 \\
\hline 1 & 1 & 3.1 \\
\hline 2 & 20 & 62.5 \\
\hline 3 & 1 & 3.1 \\
\hline
\end{tabular}

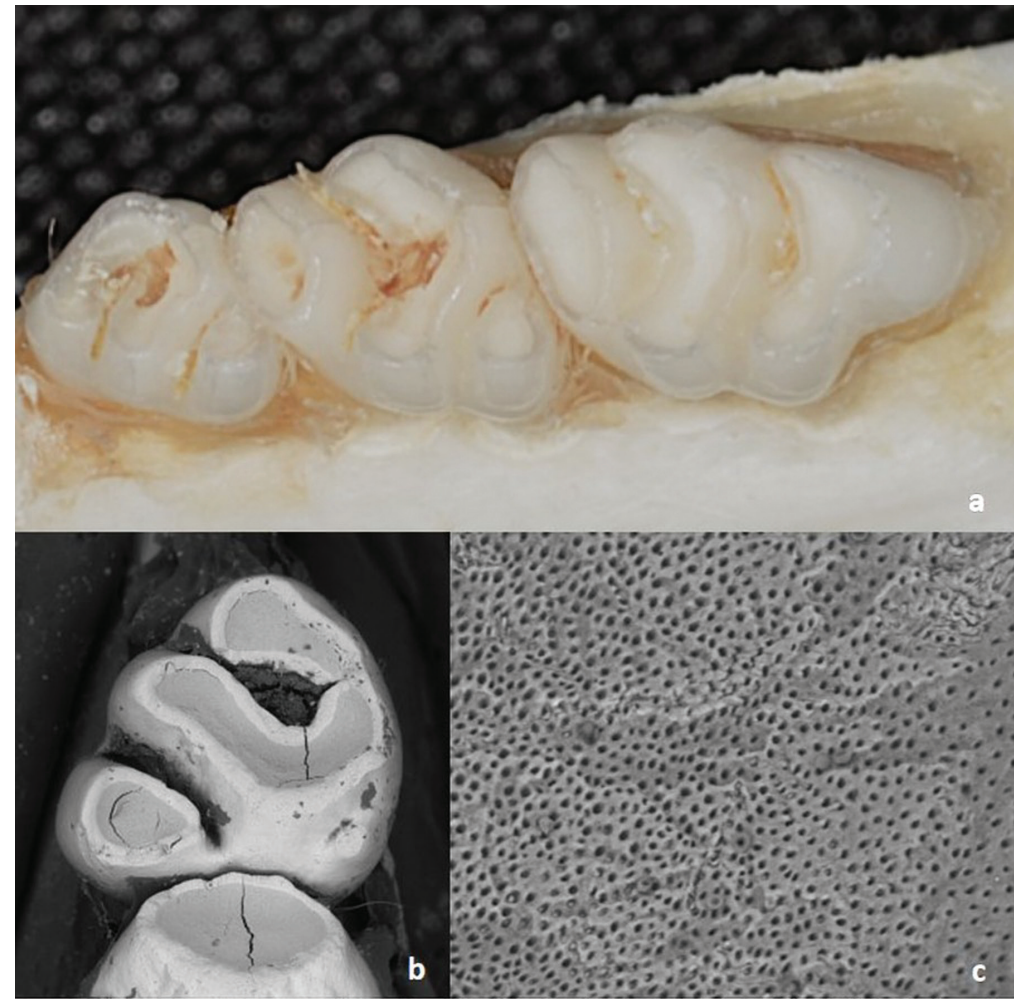

Fig. 2: Worn occlusal surface after erosion caused by the acidic isotonic drink (a), showing dentin exposure (b) an patent tubules (c).

lower in the NaF-treated groups, whether or not preceded by $\mathrm{CaL}$, in comparison to the $\mathrm{CaL}$ and negative control (DW) group (Table 2).

Photomicrographs showed that the negative control group (DW) had patent tubules (Fig. 3a). In the NaF-treated group, there was partial occlusion of dentin tubules (Fig. 3b), while in $\mathrm{CaL}$ and $\mathrm{CaL}+\mathrm{NaF}$ groups a higher proportion of tubules were occluded (Fig. 3c and $3 \mathrm{~d}$ ). In contrast to the negative control group (Fig. $3 \mathrm{e}), \mathrm{CaL}+\mathrm{NaF}$ group showed deposits inside the dentin tubules (Fig. 3f).

\section{Discussion}

$\mathrm{NaF}$ solution has been part of the strategies to mana- ge dentin hypersensitivity through the formation of deposits of $\mathrm{CaF} 2$ globules, which can physically occlude dentin tubules (10). Although dentin has the advantage to show three times higher the concentration of $\mathrm{CaF} 2$ deposits than enamel, they are unstable and desadsorb (16). In order to look towards the possibility of potentiating the effect of $\mathrm{NaF}$ solution in the context of $\mathrm{DH}$, in this study we investigated whether CaL pre-rinse would reduce the permeability of hypersensitive dentin.

As the creation of erosive lesions under controlled conditions to induce DH would be unfeasible in humans,an animal model was adopted. Rats were used because the number of dentin tubules found in rat dentin is comparable to those found in human dentin (17). By using a 
Table 2: Dentin permeability of each group presented as the mean (standard deviation) of the measurement of the stained area $\left(\mu \mathrm{m}^{2}\right)$.

\begin{tabular}{|l|l|}
\hline Group & \multicolumn{1}{|c|}{ Mean (sd) } \\
\hline Sodium fluoride $(\mathrm{NaF})$ & $4111.7(2450.6) \mathrm{a}$ \\
\hline Calcium lactate $(\mathrm{CaL})$ & $42254.6(30399.2) \mathrm{b}$ \\
\hline Sodium fluoride followed by calcium lactate $(\mathrm{CaL}+\mathrm{NaF})$ & $3405.7(1796.4) \mathrm{a}$ \\
\hline Distilled water $(\mathrm{DW})$ & $37064.6(21994.4) \mathrm{b}$ \\
\hline
\end{tabular}

Means followed by different lowercase letters differ from each other.
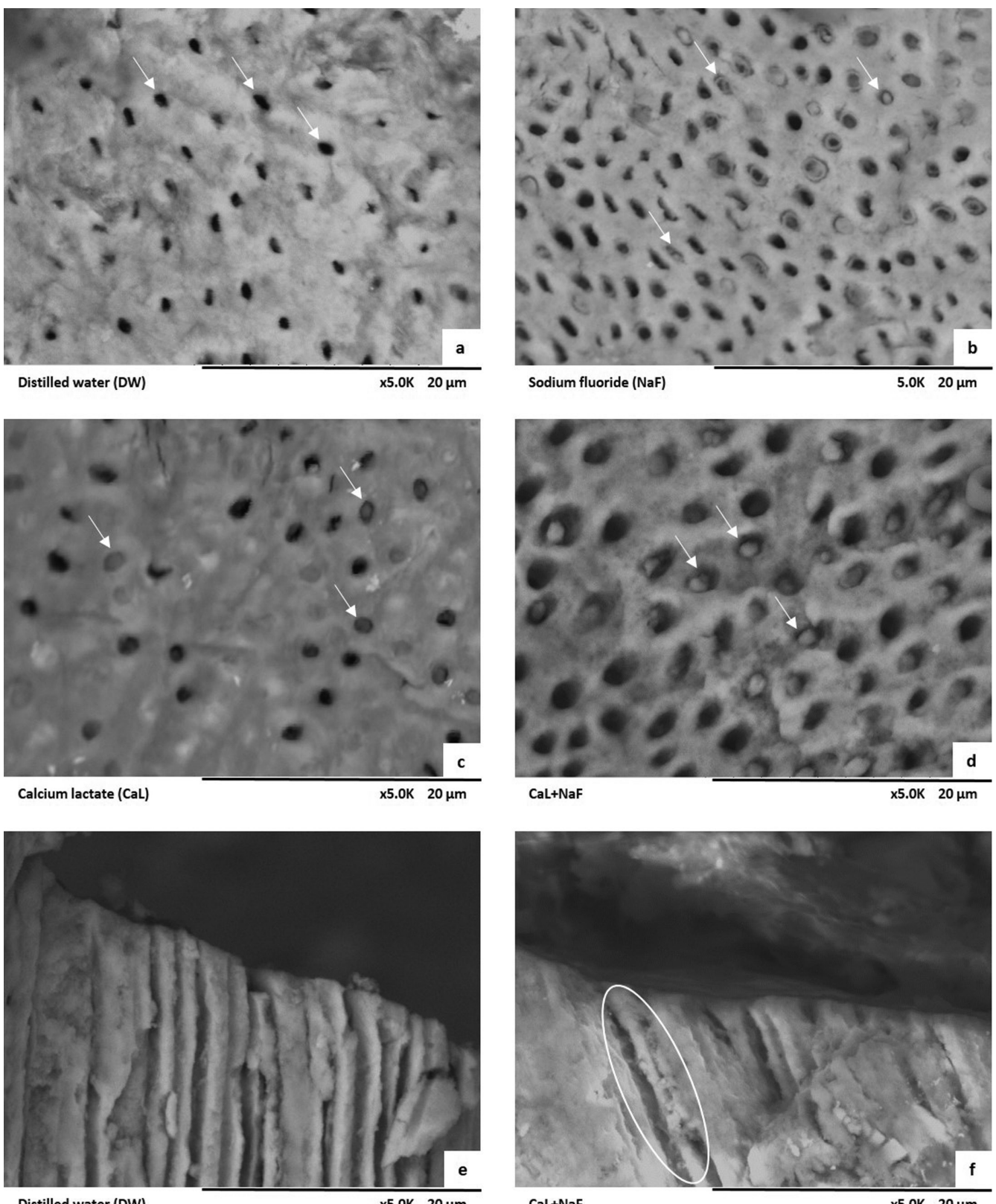

Distilled water (DW)

$\times 5.0 \mathrm{~K} 20 \mu \mathrm{m}$

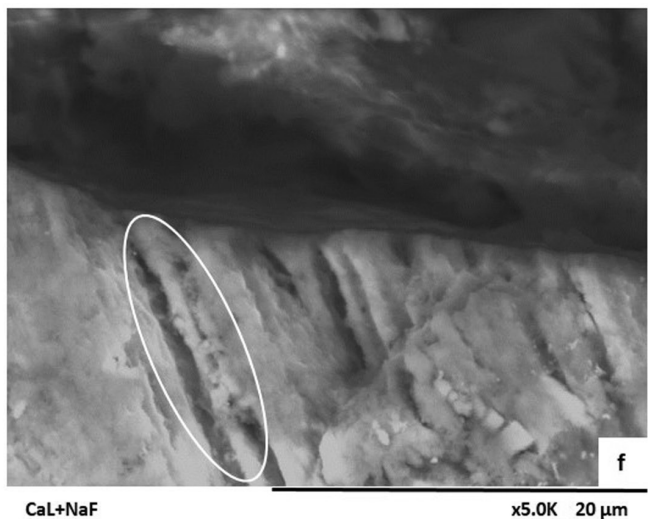

Fig. 3: Scanning electron microscopy images (5,000x and 2,000x magnification) showing the negative control group (a), with patent tubules (arrows); $\mathrm{NaF}, \mathrm{CaL}$ and $\mathrm{CaL}+\mathrm{NaF}$ groups with partially occluded dentin tubules (b, c, d); inside dentin tubules of the negative control group (e) with no deposits; and CaL+NaF group (f) with deposits partially occluding tubules. 
rat model previously described (13), DH was developed after the creation of erosive lesions using an acidic isotonic drink.

It is worth mentioning that the erosive potential of the isotonic drink used in this study has also been demonstrated in laboratory studies $(18,19)$. In addition to the low $\mathrm{pH}$ and high titratable acidity (20), the erosive potential of the isotonic drink has been attributed to its reduced $\mathrm{Ca}$ content (19). Figures $2 \mathrm{a}$ and $\mathrm{b}$ substantiates the surface loss of the rats' molars and dentin exposure caused by the intake of acidic isotonic drink.

The induction of DH was confirmed by the animal's response to pain to cold water application on their molar teeth, corroborating the results found elsewhere (13). In the present research, most of the animals, as in the quoted study, presented the second highest pain score (score 2 ) in the sensitivity scale. Thus, the results found confirmed that the isotonic drink intake, in fact, induced DH. The exposed dentin were then treated with $\mathrm{NaF}, \mathrm{CaL}$, $\mathrm{CaL}+\mathrm{NaF}$ or $\mathrm{DW}$ in order to compare their capacity to increase tubule occlusion, i.e, reduce dentin permeability. It was observed that the lowest permeability values was seen after $\mathrm{NaF}$ treatment, whether or not preceded by CaL solution. In fact, as can be seen in the SEM photomicrographs, dentin tubules was partially occluded in both $\mathrm{NaF}$-treated groups. This result is similar to in vitro and in vivo studies that evaluated the efficacy of fluoride products in the management of DH and found that these products decrease dentin permeability but produced only partial occlusion of dentin tubules $(17,21)$.

The fact that $\mathrm{CaL}$ did not enhance the effect of $\mathrm{NaF}$ in reducing dentin permeability can be explained by the discrepancy between the dentine tubule size and $\mathrm{CaF} 2$ globules, which are smaller. Thus, one can hypothesize that even in the presence of deposits of $\mathrm{CaF} 2$ globules on intertubular dentin and inside the dentin tubules, diffusion of cooper sulphate occurred through spaces between globules. Although one cannot rule out that the single application of the $\mathrm{CaL}$ pre-rinse may have contributed to the lack of its benefit in enhancing the $\mathrm{NaF}$ action, the single application was intended to avoid the necessity of multiple anesthesia to apply the solutions in the oral cavity of the animals. Further studies are warranted to evaluate whether the application of $\mathrm{CaL}+\mathrm{NaF}$ repeatedly would promote an improvement in the occluding capacity of dentin tubules, reducing dentin permeability. By examining the SEM photomicrographs one can notice that samples treated with DW water showed patent dentin tubules. In contrast, in the NaF-treated groups, associated or not to $\mathrm{CaL}$, there was partial occlusion of various dentin tubules. It can also be seen that the $\mathrm{CaL}+\mathrm{NaF}$ group presented an increased proportion of occluded dentin tubules in comparison to the NaF-only group. When evaluating inside the tubules of the $\mathrm{CaL}+\mathrm{NaF}$ group, deposits of mineral content was obser- ved, causing partial obliteration, unlike the DW group, in which tubules are patent.

Several studies have evaluated the effect of Ca pre-rinse associated with $\mathrm{NaF}$ on caries control $(22,23)$ and against erosive episodes $(11,12,24)$ with promising results. According to the current findings, although $\mathrm{CaL}$ solution seems to increase tubular occlusion provided by the $\mathrm{NaF}$ solution, its effectiveness in controlling permeability of hypersensitive dentin was not statistically superior to that found for the NaF-only group. One should bear in mind, however, that although $\mathrm{CaF}$ solution did not significantly enhance the action of $\mathrm{NaF}$ solution in reducing dentin permeability, $\mathrm{CaL}+\mathrm{NaF}$ made dentin approximately $21 \%$ less permeable than the NaF-only. Yet the impact of such reduction remains unknown, chances are that clinically it may be related to a decrease in hypersensitivity intensity.

According to the adopted animal model, it was concluded that although qualitatively there seems to be a benefit in using CaL pre-rinse, this solution did not quantitatively enhance the capacity of $\mathrm{NaF}$ in reducing permeability of hypersensitive dentin.

\section{References}

1. Kassebaum NJ, Bernabé E, Dahiya M, Bhandari B, Murray CJL, Marcenes W. Global burden of untreated caries: a systematic review and meta-regression. J Dent Res. 2015;94:650-8.

2. Senna P, Del Bel Cury A, Rosing C. Non-carious cervical lesions and occlusion: a systematic review of clinical studies. J Oral Rehabil. 2012;39:450-62.

3. Igarashi Y, Yoshida S, Kanazawa E. The prevalence and morphological types of non-carious cervical lesions (NCCL) in a contemporary sample of people. Odontology. 2017;105:443-52.

4. Douglas-de-Oliveira DW, Vitor GP, Silveira JO, Martins CC, Costa FO, Cota LOM. Effect of dentin hypersensitivity treatment on oral health related quality of life - A systematic review and meta-analysis. J Dent. 2018;71:1-8.

5. Yoshizaki KT, Francisconi-Dos-Rios LF, Sobral MA, Aranha AC, Mendes FM, Scaramucci T. Clinical features and factors associated with non-carious cervical lesions and dentin hypersensitivity. J Oral Rehabil. 2017;44:112-118.

6. Alcântara PM, Barroso NFF, Botelho AM, Douglas-de-Oliveira DW, Gonçalves PF, Flecha OD. Associated factors to cervical dentin hypersensitivity in adults: a transversal study. BMC Oral Health. 2018;18:155.

7. Costa RSA, Rios SF, Moura MS, Jardim JJ, Maltz M, Haas NA. Prevalence and risk indicators of dentin hypersensitivity in adult and elderly populations From Porto Alegre, Brazil. J Periodontology. 2014;85:1247-58.

8. West N, Seong J, Davies M. Dentine hypersensitivity. Monogr Oral Sci. 2014;25:108-22.

9. Moraschini V, Costa LS, Santos GO. Effectiveness for dentin hypersensitivity treatment of non-carious cervical lesions: a meta-analysis. Clin Oral Investig. 2018;22:617-31.

10. Petersson LG. The role of fluoride in the preventive management of dentin hypersensitivity and root caries. Clin Oral Investig. 2013;17 Suppl 1:S63-71.

11. Borges AB, Scaramucci T, Lippert F, Zero DT, Hara AT. Erosion protection by calcium lactate/sodium fluoride rinses under different salivary flows in vitro. Caries Res. 2014;48:193-9.

12. Turssi CP, Hara AT, Amaral FL, França FM, Basting RT. Calcium lactate pre-rinse increased fluoride protection against enamel erosion in a randomized controlled in situ trial. J Dent. 2014;42:534-9. 
13. Bergamini MR, Bernardi MM, Sufredini IB, Ciaramicoli MT, Kodama RM, Kabadayan F, et al. Dentin hypersensitivity induces anxiety and increases corticosterone serum levels in rats. Life Sci. 2014;98:96102.

14. Rendjova V, Gjorgoski I, Ristoski T, Apostolska S. In vivo study of pulp reaction to glass ionomer cements and dentin adhesives. Prilozi. 2012;33:265-77.

15. Carrasco LD, Fröner IC, Corona SA, Pécora JD. Effect of internal bleaching agents on dentinal permeability of non-vital teeth: quantitative assessment. Dent Traumatol. 2003;19:85-9.

16. Falcão A, Masson N, Leitão TJ, Botelho JN, Ferreira-Nóbilo Nde P, Tabchoury CP, et al. Fluoride rinse effect on retention of $\mathrm{CaF} 2$ formed on enamel/dentine by fluoride application. Braz Oral Res. 2016;30. pii: S1806-83242016000100802.

17. Pinto SCS, Silveira CMM, Pochapski MT, Pilatti GL, Santos FA. Effect of desensitizing toothpastes on dentin. Braz Oral Res. 2012;26:410-7.

18. Owens BM, Kitchens M. The erosive potential of soft drinks on enamel surface substrate: an in vitro scanning electron microscopy investigation. J Contemp Dent Pract. 2007;8:11-20.

19. Ostrowska A, Szymański W, Kołodziejczyk L, Bołtacz-Rzepkowska E. Evaluation of the erosive potential of selected isotonic drinks: in vitro studies. Adv Clin Exp Med. 2016;25:1313-9.

20. Lussi A, Megert B, Shellis RP, Wang X. Analysis of the erosive effect of different dietary substances and medications. Br J Nutr. 2012;107:252-62.

21. Mockdeci H, Polonini H, Martins I, Granato AP, Raposo N, Chaves MG. Evaluation of ex vivo effectiveness of commercial desensitizing dentifrices. J Clin Exp Dent. 2017;9:503-10.

22. Vogel GL, Tenuta LM, Schumacher GE, Chow LC. A calcium prerinse required to form calcium fluoride in plaque from a sodium fluoride rinse. Caries Res. 2014;48:174-8.

23. Souza JG, Tenuta LM, Del Bel Cury AA, Nóbrega DF, Budin RR, Queiroz MX, et al. Calcium prerinse before fluoride rinse reduces enamel demineralization: an in situ caries study. Caries Res. 2016;50:372-7. 24. Aldosari MA, Scaramucci T, Liu SY, Warrick-Polackoff JM, Eckert GJ, Hara AT. Susceptibility of partially desalivated rats to erosive tooth wear by calcium-supplemented beverages. Oral Dis. 2017;24:355-62.

Acknowledgements

The authors are indebted to Tatiana Ricci and Aline Santos, for their technical assistance.

\section{Conflict of Interest}

The authors declare no conflict of interest. 